\title{
Patrimônio cultural na contemporaneidade: discussões e interlocuções sobre os campos desse saber
}

Elis Regina Barbosa Angelo* Euler David de Siqueira**

Resumo: O patrimônio enquanto prática social de construção e presentificação de identidades coletivas que expressam interesses individuais, coletivos e públicos vem, ao longo dos anos, sendo repensado e reorganizado a partir de disputas que intervêm na história, na memória e nos seus diversos sentidos, que vão sendo construídos política, econômica e socialmente. Este artigo tem o intuito de contribuir sobre as acepções teórico-metodológicas que os diversos campos do saber vêm somando na reflexão, apreensão e relativização das percepções do campo "patrimônio histórico e cultural" enquanto forma de aplicação conceitual e crítica social, a fim de ampliar os mais variados métodos e teorias sobre os "usos" do patrimônio como ferramenta de patrimonialização, conscientização e mesmo ampliação das relações do patrimônio com a sociedade. No Brasil, as discussões permeiam as áreas de Arquitetura, História, Antropologia, Arqueologia, Turismo etc., sendo mais salientes em determinados ramos por conta de sua apropriação. Como prática, independentemente das temáticas, repercutem os anseios e experiências locais, regionais e nacionais, ao passo que sinalizam os deslocamentos conceituais entre memória e valorização temporal, urgindo o desafio interdisciplinar que tangencia todas as discussões. Dessa forma,

\footnotetext{
"Professora da Universidade Federal Rural do Rio de Janeiro (UFRRJ). Doutorado em História pela Pontifícia Universidade Católica de São Paulo (PUC/SP). E-mail: elis@familiaangelo.com, http://orcid.org/0000-0003-1799-3910

"* Professor da Universidade Federal Rural do Rio de Janeiro (UFRRJ). Doutorado em Sociologia e Antropologia pela Universidade Federal do Rio de Janeiro (UFRJ). E-mail: euler.david@ufjf.edu.br, http://orcid.org/0000-0002-0985-6900
} 
Patrimônio cultural na contemporaneidade: discussões e interlocuções...

pretende-se, por meio da revisão conceitual, abordar as relações entre os diversos campos do saber que vêm se prontificando a promover o debate acerca do uso e conceito do patrimônio.

Palavras-chave: Patrimônio cultural. Teorias. Metodologias. Identidades. Memórias.

\section{กิ Introdução}

Nos últimos 40 anos, o patrimônio cultural tornou-se um disputado campo de apropriações, de lutas e afirmações identitárias, corroborando sua centralidade nos confrontos tidos como fundamentais para sujeitos e grupos sociais em diferentes lugares do Brasil, assim como do mundo, na reivindicação da preservação do passado. Frente ao processo de compressão do tempo-espaço que Anthony Giddens (1991) nomeou de globalização, verifica-se a emergência de identidades jamais antes imaginadas (CUCHE, 1996).

A explosão dos movimentos identitários marcha lado a lado com a inflação patrimonial, em que inúmeros centros de memória, como museus, por exemplo, vão sendo criados por diferentes grupos sociais tendo como mote central a preservação de seus patrimônios e a proteção ou o "resgate" de suas identidades. Diante do colapso do Estado nacional, seja como provedor ou como espaço de representação política, assim como da categoria trabalho como esfera estruturadora da classe trabalhadora, além do crescimento do turismo (AMIROU, 2000), o patrimônio tem se mostrado fundamental à reconstrução das identidades locais e regionais. Tem-se pressa em patrimonializar diante das ameaças da globalização e do risco de desaparecimento das culturas ditas populares.

Paralelamente a esse movimento que Denys Cuche (1996) chama de afirmação das identidades, e que podemos localizar mais ou menos nos anos 1970, o patrimônio também foi fortemente apropriado pelo capital e associado ao conjunto das práticas turísticas e de lazer, sempre ávido em busca de novidades, ainda mais quando marcadas pela exoticidade, como é o caso em muitas localidades (SANTOS, 2009). 
Refletir sobre o patrimônio implica, então, mover-se em um campo minado onde as posições ocupadas por aqueles que acumularam capital ao longo de sucessivas lutas são mais do que nunca contestadas. Implica também considerar novos atores emergentes que buscam subverter as regras do campo apelando para a "autenticidade" - para ficarmos em uma das categorias mais empregadas no campo do patrimônio e do turismo (SANTOS, 2009).

A própria categoria patrimônio e sua definição, ainda orientada por critérios artísticos, históricos e de excepcionalidade, para não falar da ênfase no material e no monumental, passam a ser contestadas diante de mutações em variadas áreas do social. Diferentes crises participaram, cada uma a seu modo, da mudança de estatuto do conceito de patrimônio, seja a crise dos paradigmas científico-positivistas, sejam as demais crises, como do modo de acumulação fordista-taylorista, a crise do conceito de cultura como distinção social, a consolidação da noção antropológica de cultura, a crise do Estado social e a de instituições que antes forneciam importantes referências para a construção das identidades nacionais, como a Igreja, a família burguesa, o casamento e o emprego estável, o masculino e outras, que geraram um quadro de maior flexibilidade a que o patrimônio não ficou imune.

Dessa relação, em que o patrimônio centra-se na necessidade de rememorar e ressaltar o passado como ponto de partida, percebe-se a pluralidade e amplitude do campo semântico no qual a noção e o conceito de patrimônio se situam, desde sua constituição até a contemporaneidade no país, vinculado a múltiplos campos e áreas do conhecimento e, por isso, necessitando de interlocuções múltiplas.

Entre os diversos olhares e campos do conhecimento em sua diversidade, vale ressaltar o papel e a contribuição da História na formação do patrimônio para as esferas da vida social em sua correlação com os âmbitos social, político, ideológico, cultural, econômico e ambiental. Não se trata aqui de concepções cerradas, mas como amplitudes necessárias nas configurações epistêmicas que possam cooperar em uma maior integração e interdisciplinaridade que o conceito precisa para existir e ser organizado ou compreendido pluralmente. As argumentações de Paoli (2009, p. 18) enfatizam a compreensão dos discursos diversificados das 
Patrimônio cultural na contemporaneidade: discussões e interlocuções...

áreas do conhecimento, e que em um movimento paralelo traçado entre as trajetórias da historiografia da arquitetura e da preservação do patrimônio histórico se correlacionam no passado e no presente, funcionando no benefício da produção arquitetônica do presente. Sem dúvida, trata-se de um dos caminhos para a produção do patrimônio nacional.

Entre as reflexões historiográficas que, conjugadas às reflexões de outros campos do conhecimento, contribuíram numa perspectiva interdisciplinar estão aspectos monumentais da criação humana que remetem ao universo do patrimônio da humanidade e a diversas polêmicas envolvendo a UNESCO, as relações entre a arquitetura e sua valoração, memórias afetivas mais profundas presentes em diferentes manifestações e performances artísticas de natureza imaterial ou intangível, além de suas relações intrinsecamente ligadas aos aspectos materiais e imateriais da vida social. Das principais interferências e reflexões acerca da formação do conceito clássico de patrimônio, sobressaem-se as noções de tempo, memória, cultura e sua produção e a sociedade, a fim de relacionar as noções de tempo/ identidade/pertencimento/valor/memória/espaço, para que a partir dessa se possa colaborar na experiência dos sujeitos e suas vivências com patrimônio em processo, e especialmente enquanto preservação do patrimônio e suas políticas de preservação (FONSECA, 2005).

Conforme aponta Castriotta e Araujo (2009, p. 40), ao "[...] refletir sobre a trajetória das políticas de preservação do patrimônio cultural no Brasil, não se pode deixar de refletir, simultaneamente, sobre o legado do Movimento Moderno na historiografia da arquitetura brasileira”. Assim, merece destaque a ideia de que

[...] para se compreender o predomínio dos modernos no discurso público, não basta tratar da construção dos monumentos da arquitetura, como faz a historiografia mais tradicional, mas cabe enfocar também o seu papel na criação e conservação do patrimônio cultural nacional, por meio do qual conseguem estabelecer conteúdos normativos que se tornam hegemônicos no país (CASTRIOTTA; ARAUJO, 2009, p. 41). 
Nesse sentido, as metodologias qualitativas nos auxiliam na construção de um olhar compreensivo que dê conta do papel da interpretação com todas as possibilidades de divergência. Adotamos uma abordagem relacional, própria do campo das Ciências Sociais, notadamente a sociologia e a antropologia, apesar de pontuarmos a necessidade de se repensar, a partir da historiografia, o olhar para o patrimônio, tangenciando suas diversidades e dimensões. Precisamos, portanto, corroborar "[...] os valores atribuídos ao patrimônio, que, na realidade, foram histórica e socialmente construídos" (CAVALCANTI, 1995, p. 46). As epistemes oriundas da antropologia, por exemplo, convergem para a produção de sentido ou do significado, como assinala José Reginaldo Santos Gonçalves (2007, p. 245): “Nas análises dos modernos discursos sobre o patrimônio cultural, a ênfase tem sido posta no seu caráter 'construído' ou 'inventado"'.

Nessa perspectiva de se pensar o valor atribuído ao patrimônio cultural, torna-se ímpar revisitar o conceito de forma contínua, a fim de que seja estabelecido como um campo de conjecturas movido pelo tempo e pelos augúrios do processo político e dos projetos políticos de nação, como chama atenção Marins (2016), ao corroborar a premissa de que é necessário rever as "[...] pièces de résistance do ideário modernista de desenho do Brasil, fortemente excludente" (MARINS, 2016, p. 23).

Dessa forma, concordamos/corroboramos o pensamento de Castriotta e Araujo (2009, p. 53) ao entender que a historiografia contribuiu para compor as condições de esquecimento da produção valorativa aos bens e conjuntos arquitetônicos tombados, considerando seu "contexto fortemente ideológico, no qual o discurso dominante, forjado pelos arquitetos do Movimento Moderno, logra estabelecer como absolutos valores atribuídos ao patrimônio que, na verdade, foram histórica e socialmente construídos”. E ainda buscamos que as considerações acerca dessa análise possam colaborar na compreensão das diversas manifestações e etapas da produção cultural no país, que possam exemplificar novos objetos e sujeitos na composição mais democrática para a História e memória nacionais (CASTRIOTTA; ARAUJO, 2009).

Situado entre um carrefour em que se encontram disciplinas tão distintas como a História, a Sociologia e a Antropologia, o 
objeto deste artigo não poderia deixar de ser marcado pela complexidade e ainda pela totalidade, para usar o termo criado por Marcel Mauss (1974) para falar de instituições em que diferentes fenômenos convergem sem que se perca de vista o sujeito em sua tripla natureza: fisiológica, psicológica e sociológica, mas não menos histórica. Concordando com o que Marins aponta ser necessário: "rever o desenho ideário e excludente" do patrimônio, com atenção à História e à Memória enquanto diálogos frutíferos (MARINS, 2016, p. 23).

Nosso objeto diz respeito, portanto, a um percurso antropológico em que diferentes mutações no campo do político (CLASTRES, 1992), do simbólico (GEERTZ, 1978; DURAND, 1996), do econômico (GIDDENS, 1991) e do histórico (CHARTIER, 1990) articulam-se sem serem reduzidos a uma instância hierarquicamente superior a qualquer outra. Dito de outra forma, as tensões decorrentes das diferentes transformações a que foi submetido o conceito de patrimônio e os desafios de natureza teórica e metodológica em face da emergência de novos fenômenos sociais, como aqueles relacionados ao campo das mídias, das identidades, das lutas e reivindicações de gênero e, notadamente, o corpo, demandam novos olhares e novas abordagens capazes de dar conta de sua complexidade atual.

\section{O conceito de patrimônio cultural em processo: áreas, confrontos e avanços}

O campo dos valores não é um mapa em que se tenham fronteiras demarcadas, rotas seguras, pontos de chegada precisos. É, antes, uma arena de conflito, de confronto - de avaliação, valoração. Por isso, o campo da cultura e, em consequência, o do patrimônio cultural, é um campo eminentemente político [...] (MENEZES, 2012, p. 38).

A proteção e a preservação dos bens produzidos pelas sociedades e seus diversos grupos encontram na figura do Estado moderno um ator social central, tanto no que se refere à definição quanto à sua delimitação e proteção, difundidas por uma gama de símbolos 
e atitudes que referenciam a formação de transmissão das histórias e memórias da nação nos mais variados “tempos”. Em outras palavras, Estado e patrimônio marcham lado a lado influenciando-se reciprocamente, nem sempre de maneira democrática e inclusiva.

$\mathrm{O}$ antropólogo francês Rachid Amirou assinala que o Estado, desde o primeiro momento em que o patrimônio se mostrou decisivo para a construção das identidades nacionais, colocou-se como o principal guardião da memória coletiva:

Voltemos à França para dizer que a salvaguarda do passado torna-se uma missão do Estado que assegura o monopólio quase exclusivo da proteção do patrimônio. [...] O importante para a história da arte das obras-primas da I’̂̂le de France é o primeiro critério de salvaguarda. [...] O Estado central enquanto que responsável pela memória nacional ocupa desde já uma missão de vigilância das evoluções e transformações do patrimônio (AMIROU, 2000, p. 18).

Conforme assinala Amirou, o Estado central se encarrega da missão de não somente organizar tudo o que for necessário para assegurar a identificação, seleção e proteção do que será inscrito nas listas do patrimônio, como se costuma dizer na França, como também se coloca na posição de observador das transformações sofridas pelo patrimônio ao longo do tempo. Trata-se de um ator social central cujo poder em face do patrimônio não deixa dúvidas sobre suas reais intenções no campo político. $\mathrm{O}$ patrimônio foi, dessa maneira, fortemente investido pelo Estado, tendo em vista o interesse das frações hegemônicas que o compõem.

No Brasil, a identidade nacional torna-se, nos anos 1930, um assunto capital. Afinal, tratava-se de dar conta dos desafios introduzidos pelo processo de modernização e de constituição da classe trabalhadora. No Brasil, a cultura popular foi alçada à condição de representante da identidade nacional. A cultura popular foi apropriada para erigir a identidade nacional, aspecto fundamental do projeto do Brasil como nação.

Ao refletir sobre a relação entre o Estado, a cultura popular e a identidade nacional, o antropólogo brasileiro Renato Ortiz (1994) 
mostra que toda e qualquer tentativa de totalização das diferentes culturas populares em uma identidade nacional revela aspectos da ideologia e de seu uso político por parte do Estado. Segundo Ortiz, a identidade nacional é um discurso de segunda ordem fabricado por mediadores simbólicos ou ideólogos situados dentro ou fora do Estado, cuja finalidade é tomar aspectos selecionados das culturas populares concretas com vistas à sua universalização ou ainda homogeneização. É nesse sentido que Ortiz opõe cultura à ideologia, pois, enquanto a cultura implica a vivência concreta e cotidiana de seus mitos e ritos por parte de seus membros, a ideologia se reveste de um discurso ausente de contradições, cuja forma busca retomar no nível do Estado o que o mito representa no universo dos grupos sociais tradicionais.

A escolha da cultura popular para figurar como elemento formador da identidade nacional se deu mediante o argumento da forte miscigenação presente na formação do povo brasileiro. A ideia de povo é uma constante no pensamento de nossos primeiros intelectuais. Essa é uma ideia que já estava posta desde a segunda metade do século XIX para intelectuais como Silvio Romero, Nina Rodrigues e Euclides da Cunha, entre outros, avança Ortiz (1994; SIQUEIRA, SIQUEIRA, 2012). Seriam os intelectuais ou mediadores simbólicos, ação orientada politicamente, afirma Ortiz, que estariam à frente da seleção de traços das culturas populares, universalizando-as a toda a sociedade.

A crítica da memória nacional como extensão da memória coletiva, própria das culturas populares, é tributária da compreensão do Estado como agente político que busca cimentar as fissuras e rachaduras de uma sociedade diferenciada pelo processo de divisão social do trabalho. As consequências desse tipo de operação deixaram marcas ainda observáveis na forma como patrimônio e identidade são refletidos em termos de representantes da brasilidade (ORTIZ, 1994).

No bojo do jogo político é que se situam as relações entre os diferentes grupos sociais que constituem a nação, que se observam a partir das disputas não só político-ideológicas, mas também institucionais em torno, principalmente, das noções de memória e identidade, cujos vínculos com a perspectiva de patrimonialização 
são bastante estreitos. Há de se destacar ainda que, em fins do século XVIII, lugares e objetos foram colocados em evidência, especialmente porque o processo consciente de conservar o passado toma forma por meio da história ou da arte (CHOAY, 2001).

$\mathrm{Na}$ esteira do pensamento de Françoise Choay (1999), Gravari-Barbas e Philippe Violier (2003) destacam aspectos do processo de tomada de consciência de sua própria cultura, empregando, para isso, o termo instrumentalização cultural. Ambos os autores deixam claro que esse processo de instrumentalizar aspectos culturais não é novo e, ademais, pode ser encontrado em inúmeras sociedades. Além disso, não somente atores sociais ditos culturais participam desse processo, mas também uma "multitude de atores (não necessariamente culturais) para fins de desenvolvimento econômico, de pacificação social, de marketing territorial, de organização urbana" (GRAVARI-BARBAS; VIOLIER, 2003, p. 10, tradução nossa).

Essa perspectiva chega ao Brasil em meados do século XX e é discutida a partir do Movimento Modernista, com especial atenção ao discurso de nação e nacionalismo, pormenorizando a questão da identidade nacional. Delineiam-se, assim, princípios e concepções políticas sobre o passado com vistas ao resgate da "nação brasileira" a partir das culturas populares, notadamente. A imposição de princípios e moldes de políticas de patrimônio que direcionaram o discurso sobre o futuro da arquitetura confere-lhe valores históricos e sociais, e esses, por sinal, vinculam-se à apreensão da perspectiva patrimonial no Brasil (CAVALCANTI, 1995).

Cabe salientar que, a partir da construção da perspectiva patrimonial no Brasil, pela concepção de Mário de Andrade em seu anteprojeto, o patrimônio se forma com base na arte. E, ao ser expresso pelas manifestações eruditas e populares de caráter diametralmente dicotômico entre o particular e o nacional, precisa ser compreendido pela sua autenticidade, unidade e referência (ANDRADE, 1972; 1981).

Para melhor percepção do alcance desse movimento em torno da perspectiva de patrimônio, vale realçar a reflexão de Choay (2001) a respeito do culto ao monumento. A autora identifica um olhar diretivo a partir do sentido e dos significados históricos apregoados a ele por meio da interpretação: "Só a investigação do sentido ou 
Patrimônio cultural na contemporaneidade: discussões e interlocuções...

dos sentidos atribuídos pela sociedade ao monumento histórico permite fundar uma prática. Daí uma dupla abordagem - histórica e interpretativa" (CHOAY, 2001, p. 168).

É importante sublinhar também que, na contemporaneidade, o campo semântico amplo que marca a noção de patrimônio é resultante das diversas formas de percepção, interpretação, apreensão e experimentação da perspectiva de patrimonialização que os grupos sociais vivenciam. Trata-se de perspectiva que dialoga e se associa aos processos de uso, apropriação e preservação do patrimônio e se vincula de forma muito estreita a questões e vivências relativas à memória, à identidade, ao "tempo", à cultura e à própria história.

Diversas são, portanto, as formas de ver e interpretar o conceito e a concepção do que é patrimônio, já que os elementos referenciados podem ser tomados sob perspectivas muito distintas em virtude dos lugares de enunciação dos quais emanam. Mas é precisamente diante da abertura e da possibilidade ampla acordada ao conceito de patrimônio que surgem questões sobre seus limites e alcances, quando não é o caso de sua validade heurística ou da perda de sua capacidade analítica (AMIROU, 2000; GONÇALVES, 2007).

Podem-se observar aspectos dessa discussão em trabalhos concretos, como $A$ festa ou o fetiche, o gesto ou a gestão: o patrimônio cultural imaterial como efeito perverso da democratização, em que Dorothy Noyes (2011) investiga o processo de patrimonialização de uma tradição festiva na Catalunha, Espanha: a Patum de Berga. Segundo Noyes (2011, p. 127), é uma forte crítica da forma como a noção de patrimônio imaterial (PCI - Patrimônio Cultural Imaterial) é utilizada junto às tradições orais e gestuais: "A Patum figura entre as últimas 'obras de arte do Patrimônio oral e imaterial da humanidade' [...] uma série de danças de máscaras e figuras esculpidas, a Patum propriamente dita, que se repetem várias vezes durante cinco dias sobre a praça central da cidade.”

Conforme avança Noyes, a candidatura da festa de Patum como patrimônio cultural imaterial da humanidade suscitou inúmeras contradições. A primeira delas dizia respeito à instrumentalização da festa como argumento para movimentar a economia da cidade espanhola de Berga. A segunda referia-se à criação de um patronato para gerir a festa e cujo resultado mais imediato foi afastar os 
participantes, eles mesmos os mais interessados na patrimonialização, segundo seus promotores. Em terceiro lugar, a transformação da festa em um produto a ser explorado pelas empresas. Como sublinha a autora:

A patrimonialização da Patum reconstituiu, entretanto, a festa viva como fetiche e o gesto social cedeu, diante da gestão profissional, tendo na [...] naturalização do patrimônio como único destino das tradições populares a ser perseguido tão rápido quanto possível é perigoso; ousa-se dizer que ela poderia prejudicar as missões essenciais da UNESCO (NOYES, 2011, p. 142).

Conforme destaca Noyes, ao contrário de envolver os atores sociais locais, o processo de patrimonialização da Patum os afastou ao valorizar mais os efeitos advindos do processo de sua inscrição na lista do patrimônio do que os valores, práticas e representações sociais em si mesmos. A burocratização da festa foi outro duro golpe na forma como a população local se apropriava da festa. Finalmente, a transformação da festa em marca ou ainda em uma mercadoria desconectada dos membros da coletividade terminou por criar um fosso entre aqueles mais envolvidos pela patrimonialização e aqueles interessados nesse processo do ponto de vista administrativo ou econômico.

Essa correlação, ao ser posta à prova das diversas ciências e saberes, torna-se uma incógnita sobre os direcionamentos mais plausíveis na valorização do passado e dos saberes e fazeres, como a festa em questão. Assim, percebe-se que, além da complexa noção de patrimônio recebida de campos como a História, que trouxe importantes contribuições na relativização do conceito, as quais aparecem, inclusive, apropriadas por diferentes movimentos espontâneos da sociedade civil, em busca do resgate de sua própria identidade mediante sua valorização, ainda requer contribuições múltiplas para seu futuro (MENEZES, 2012).

Referenciais historiográficos estão sendo permanentemente apropriados e experimentados pelos diferentes grupos sociais quando estes se deparam com a descoberta dos mecanismos de 
patrimonialização de um bem, seja ele de natureza material ou imaterial. Contudo, há sempre o risco de que esses processos desconectem aqueles que sustentam as práticas e representações sociais que se querem valorizar e aqueles que falam em seu nome, como mostra a análise de Noyes (2011).

Em um tempo em que a referência de globalização constitui-se como unidade e recolocam-se questões relativas à valorização das especificidades locais, é na tênue fronteira entre a inserção do local no global que se percebe a constituição de outra fronteira. Fronteira sutil que cresce e se difunde atualmente de forma expressiva. Trata-se da fronteira entre os novos mecanismos teórico-metodológicos que o campo da História e outras áreas do conhecimento difundem e as próprias demandas sociais que se vinculam aos processos crescentes de patrimonialização em curso no âmbito do próprio vivido. Como assinala o antropólogo brasileiro Ruben Oliven (2009, p. 80), "[...] para preservar, precisamos, antes, classificar e colecionar. Por isso, temos agentes que detêm o poder legítimo de definir o que faz parte do patrimônio. Esses guardiães do patrimônio definem o que é digno de ser preservado".

A busca pela preservação da memória tem sido um dos caminhos pelos quais a sociedade vem retomando a sua história e seu passado. Nessa esfera, traduzida como "tempo presente" ou, como Reinhart Koselleck define, um tempo emaranhado numa infinitude de momentos, passado, presente e futuro vão sendo aproximados por algumas ações, entre elas a ideia do que é patrimônio e o direito à memória ou ao passado.

A memória, tida como algo que ocorre no passado e o representa, passa a ser como um fio que conduz à referência cronológica e temporalmente. Nesse sentido, as reflexões de Paul Ricoeur (2007) abrem novas perspectivas para a percepção e apreensão da memória, já que para o autor a memória não significa apenas uma ferramenta de rememoração, mas algo capaz de produzir o reconfigurar das coisas e dos processos. Trata-se de percepção fundamental para melhor apreender os movimentos espontâneos da sociedade civil em busca da constituição de sua própria identidade. Reconfiguram-se a todo o momento elementos de uma identidade local sob o ponto de vista da cultura em sua acepção antropológica, com vistas a 
integrá-los a uma identidade global. É importante destacar ainda que, no fluxo desse movimento contemporâneo, o próprio conceito de patrimônio emerge como uma categoria importante para a (re) construção da(s) memória(s) e da(s) identidade(s).

\section{Entre a memória, a história e o patrimônio: questões e contribuições teórico-metodológicas e políticas de preservação}

Ao referenciar a necessidade de ampliação do conceito e de uso do patrimônio cultural na contemporaneidade, as políticas de preservação vêm sendo prioridade no que tange à utilização do bem ou à sua salvaguarda. No Brasil, algumas referências e contribuições se tornaram ímpares na condução das discussões. Entre os referenciais estão as obras de Chuva (2003), Fonseca (2005), Julião (2009), Magalhães (2007), Miceli (2001), Pelegrini (2008), Schwarcz (1989), Scifoni (2006), entre outros.

Dessas contribuições, destacamos a de Fonseca (2005), com a análise do patrimônio como um processo em constante lapidação, e a de Miceli (2001), que nos apresenta a produção intelectual acerca do conceito de patrimônio cultural e a construção das relações político-ideológicas e sugestivas das correlações entre os âmbitos pelos demais autores, corroborando a principal vertente da investigação sobre o tema nada consensual do espaço da preservação. Sendo o patrimônio cultural um emaranhado de concepções tangenciadas pela relação memória $\mathrm{x}$ história da sociedade temporalmente construída sob julgamento de "valores", pode-se afirmar que na relação conceitual do espaço em que o patrimônio transita e se inscreve, ou seja, no espaço social, onde os grupos sociais negociam significados e onde se formam disputas simbólicas por distinção, ocorre a legitimidade cultural (BOURDIEU, 2007).

A contribuição do pensamento bourdieusiano ao campo do patrimônio e da memória se mostra importante por vários motivos, sendo a noção de habitus certamente uma das mais significativas. Entendido como disposições duráveis e transferíveis, o habitus é a 
lei ou a regra feita "homem" (BOURDIEU, 2000). Dito de outra forma, é a outra face da estrutura social que, depois de ser objetivada em instituições sociais como o Estado e a burocracia, a Igreja e o capitalismo, é incorporada pelos sujeitos, tornando-se carne. Entre o habitus, estrutura estruturante incorporada, e o campo, ou estrutura estruturada objetivada, haveria homologias. O habitus unificaria os dois polos frequentemente vistos de maneira antagônica através de oposições do tipo: natureza x cultura; indivíduo x sociedade, subjetividade $\mathrm{x}$ objetividade; estrutura $\mathrm{x}$ ação; etc. Assim, as ações e condutas dos agentes sociais, longe de encerrarem qualquer tipo de escolha ou deliberação, seja ela consciente ou inconsciente, racional ou irracional, nada mais seriam do que um tipo de ajustamento em termos de expectativas entre o habitus e o campo onde a socialização se processou.

Conforme assinala Pierre Bourdieu (2000), o habitus é o sentido do jogo. Em outras palavras, trata-se de antecipações regradas que os sujeitos realizam no ato do jogo e que em nenhuma hipótese se devem a um cálculo racional visando a um fim ou tendo um objetivo previamente intencionado. Ao contrário de uma sobredeterminação da estrutura sobre a ação, Bourdieu refletiu sobre os limites do habitus sem, contudo, fechá-lo em um círculo sem saída. Não se pode escolher ou fazer além do que é delimitado pelo habitus, entretanto, não se trata de obedecer cegamente a um plano predeterminado. O habitus permite alguma criatividade para além das determinações de classe, o que nos remete ao universo do patrimônio como campo de possibilidades.

A construção do conceito de patrimônio cultural parece envolver uma constante disputa de significados temporalmente constituídos, pois, além dessa afirmação, parte-se da ideia de que seu campo dimensional se forma a partir de processos de legitimação institucionalizados, e essa faz parte das maneiras como os processos de tombamento e registro são calçados. Suas formas e contornos, amparados na legislação e suas ramificações legais como padronizações, direções e apreensões, acabam legitimando "oficialmente" o que é e como deve se comportar o patrimônio cultural ao longo do tempo. Contudo, há de se conceber os sujeitos e suas 
estratégias como formas de resistência que criam alternativas aos aspectos institucionalizados.

Conforme podemos ler em Fonseca (2005, p. 58), a “[...] idéia de posse coletiva como exercício da cidadania inspirou a utilização do termo patrimônio para designar o conjunto de bens de valor cultural que passaram a ser propriedade da nação [...]”. Dessa forma, a autora credita o valor atribuído coletivamente ao patrimônio como uma relação entre a memória enquanto valor do passado e a construção de identidades legitimadas a partir dos instrumentos legais que a nação moderna ratifica.

O modo como lugares e momentos de uma realidade social existem define-se, especialmente, com base no valor a eles atribuído na ocasião em que são pensados, criados e definidos (CHARTIER, 1990). É, portanto, no campo da própria História, quer como "realidade", quer como "escrita da história" ou como produção de sentido (GONÇALVES, 2007), que se constituem os "bens patrimoniais". Convém sublinhar que o conceito histórico moderno de patrimônio associa-se de forma particular ao que Eric Hobsbawm denomina de Estado-nação. Essa experiência política é permeada pela "retórica da perda”, que se constitui como uma articulação entre o domínio/ Estado e o coletivo/contraponto e reticência.

É importante considerar também que esse Estado-nação, com o intuito da salvaguarda calcada na ideia de povo no território e no tempo, busca a manutenção da memória coletiva pela representatividade histórica do monumento no tempo (CHOAY, 2001). Essa perspectiva, que discute a necessidade de manutenção de uma memória coletiva, é um símbolo do que está em perigo e necessita de salvaguarda, daí a concepção de que o patrimônio é a valorização do passado por meio de sua história cristalizada no tempo, especialmente por meio do monumento/documento, ou pela ideia de alegoria. Essa ideia, por sinal, parte do princípio de que o patrimônio representa algo fora do seu tempo, ou seja, representa algo cujo sentido é significado como outro em temporalidade distinta (GONÇALVES, 2002). É por isso que as questões que atravessam a criação, afirmação, propagação e apropriação dos "bens" escolhidos pelos grupos sociais para se constituírem como 
Patrimônio cultural na contemporaneidade: discussões e interlocuções...

"lugares de memória", como assevera Pierre Nora, encontram-se situadas entre a História e o Patrimônio (NORA, 1993).

Euler David de Siqueira (2016), em reflexão acerca da identidade, da cultura e do patrimônio na pós-modernidade, pontua esse movimento de redefinição da perspectiva patrimonial e destaca a crescente difusão do que classifica como "novos patrimônios". Em se tratando do caso francês, Amirou (2000) sublinha o fenômeno do grande interesse em patrimonializar espécies vegetais e animais na França, quando não também produtos como queijos, embutidos e mesmo objetos produzidos em regiões da França que acabam sendo fortemente identificadas a esses signos-bens. Amirou (2000) comenta ainda que as localidades turísticas dependem frequentemente de um imaginário social para se edificarem, ao qual, contudo, administradores e gestores não estão familiarizados, principalmente no que diz respeito aos fatores antropológicos.

Embora o patrimônio seja uma dessas categorias ditas universais presentes em todas as configurações culturais, conforme assinala José Reginaldo Santos Gonçalves (2009), foi somente em fins do século XVIII, com a Revolução Francesa, que emergiu no Ocidente uma forma de consciência fortemente preocupada com o desaparecimento daquilo que poderia ser mais caro a uma nação. Em outras palavras, nascia isso que muitos analistas chamam de a retórica da perda e, consequentemente, o patrimônio (CHOAY, 1999; AMIROU, 2000; GONÇALVES, 2009).

Desde então, temos observado uma verdadeira inflação dos processos de patrimonialização, cujos efeitos, certamente, ainda não podem ser conhecidos e avaliados inteiramente. Um dos exemplos do tipo de relação que sublinhamos é abordado por Luciana Silveira e Mercedes Buendia em Da invenção da tradição (ou de como os patrimônios nos inventam): notas sobre a patrimonialização do pastoreio na Espanha. Nesse estudo de caso, as autoras discutem o processo de patrimonialização da transumância em uma localidade do norte da Espanha em face da "ameaça" de desaparecimento dessa importante instituição social dos países mediterrâneos. Trata-se de uma investigação em que se articula a construção de identidades em sua relação com políticas públicas de valorização do patrimônio (SILVEIRA; BUENDIA, 2011). 
Uma vez soado o alerta de risco do desaparecimento da transumância, mobilizam-se diferentes instituições e profissionais cujos discursos assinalam os incontáveis fatos positivos produzidos pela atividade pastoril. Entre os principais argumentos estão aqueles que assinalam o papel central da transumância para a continuidade da natureza e da cultura. Do ponto de vista da interação homem-natureza, diz-se que a transumância favorece a biodiversidade, a dispersão de sementes, o sequestro de carbono, a diminuição dos incêndios florestais e mesmo a paisagem. Do ponto de vista econômico, a transumância é apontada como responsável pela fixação do homem no campo, pela diminuição do êxodo rural e pelo desenvolvimento rural, pela economia das famílias locais, etc. No que diz respeito ao contexto histórico-cultural, os pastores aparecem como atores que sempre mantiveram uma relação direta com a natureza; eles são situados assim como herdeiros de um saber e memória ancestrais, cujas práticas asseguram a manutenção de corredores ecoculturais que protegem a natureza e, como não poderia deixar de ser, a cultura (SILVEIRA; BUENDIA, 2011).

É interessante observar as combinações feitas entre as noções de patrimônio natural e cultural e a compreensão do fenômeno investigado na citada obra de Luciana Silveira e Mercedes Buendia (2011). Tal investimento somente foi possível com o alargamento da noção de patrimônio, notadamente em sua vertente imaterial. As autoras ressaltam também o papel que os objetos representam na constituição do fenômeno patrimonial, na medida em que roupas, utensílios, ferramentas, etc., ajudam a compor a figura do pastor. Outro aspecto importante no trabalho das autoras diz respeito às interfaces entre os saberes-fazeres relacionados às práticas dos pastores e a noção de autenticidade, ainda fortemente presente nos discursos patrimoniais. Os pastores são desenhados nos discursos patrimoniais como detentores de técnicas corporais, no sentido atribuído por Marcel Mauss, fundamentais em sua relação com a natureza: animais, eventos climáticos, ferramentas, saber-fazer gastronômico etc.

Um dos saberes-fazeres de grande importância é o preparo do queijo chamado gamoneu ou gamonedo (SILVEIRA; BUENDIA, 2011). De acordo com as autoras, ainda que o queijo seja fabricado 
industrialmente, somente o fabricado pelos pastores é reconhecido como "autêntico", pois é artesanal, o que expressaria de forma inconfundível o terroir local. O risco de desaparecimento do pastoreio carrega consigo também o de perda do saber-fazer do queijo artesanal tão valorizado e apreciado, pois está associado tanto à manutenção da biodiversidade quanto da sustentabilidade. E, "dessa forma, o queijo gamoneu tem se consolidado como símbolo não apenas do "pastor transumante", mas também das ações de preservação da natureza e do patrimônio histórico-cultural da Espanha" (SILVEIRA; BUENDIA, 2011, p. 158).

A patrimonialização da transumância e todo o complexo de práticas, técnicas corporais, habitus, memórias, imagens e imaginários que se organizam ao seu redor têm menos a ver com o resgate de um passado idealizado e mais com a ressignificação de elementos hierarquicamente valorizados que são selecionados para figurarem em fronteiras étnicas. Nas palavras das autoras:

[...] a relação entre as comunidades atuais e as do passado se dá por meio da seleção e da recriação de aspectos da memória, de traços emblemáticos capazes de atuar como sinais externos de reconhecimento [...] é através da manipulação de determinados objetos, artefatos, performances relacionados à cultura pastoril que se obtém recursos para a ação: a cultura material e seus aspectos ideológicos são ressignificados e passam a deter um valor de extrema importância na delimitação das fronteiras identitárias, bem como para a constituição dos projetos políticos dos atores envolvidos com o processo de patrimonialização do pastoreio (SILVEIRA; BUENDIA, 2011, p. 166).

Alguns dos efeitos produzidos pelo processo de patrimonialização mostram que os pastores tiveram sua autoestima elevada, sentindo-se mais empoderados em suas negociações com o poder público. Da mesma forma, passam a receber a atenção de turistas, que os veem como guardiões da cultura e memória tradicionais. As identidades, erguidas em bases étnicas, isto é, como fronteiras delimitadas na oposição contrastiva, implicam escolhas e seleções, 
mas, advertem as autoras, não se reduzem à sua dimensão instrumental. Em outras palavras, outros fatores atuam nesse processo cujo controle dos meios jamais é total e consciente.

As razões elencadas para dar conta do vertiginoso aumento da patrimonialização são muitas, mas, ao lado da ameaça da suposta perda, sempre presente nos discursos associados aos processos de patrimonialização, também é preciso destacar aquelas resultantes do que se chama globalização, na falta de um nome mais apropriado. Noção vaga e imprecisa, mas que nas plumas de muitos analistas serve para explicar de tudo um pouco, a globalização atua fortemente junto aos processos de localização, uma das muitas reações ao global. De acordo com Maria Gravari-Barbas e Philippe Violer (2003, p. 9, tradução nossa), "[...] as sociedades contemporâneas são confrontadas a um duplo movimento de globalização e de localização. Quanto mais a produção cultural transcende as fronteiras nacionais e sociais, mais ela se reconstrói por uma reativação forte das culturas regionais e locais".

Vários trabalhos investigam a forma como a valorização do patrimônio gastronômico se articula aos processos de valorização identitária frente a uma ameaça homogeneizadora. $\mathrm{O}$ trabalho de Olivier Etcheverria (2003) observa o processo de reinvenção ou ressignificação do presunto cru por parte do País Basco. Segundo Etcheverria, o porco é um elemento importante da culinária basca por vários motivos. Em cada família ao menos uma pessoa era detentora de um savoir-faire tradicional ligado ao ato de matar o porco e de prepará-lo segundo as tradições transmitidas pelos mais velhos aos mais jovens. Conforme Etcheverria, o ato de matar o porco revestia-se para além de um simples ato prático-instrumental. Significava, acima de tudo, um formidável momento de sociabilização e de troca de experiências embebido em grande efervescência nada devedora a qualquer culto religioso.

De acordo com Etcheverria (2003, p. 39, tradução livre), "o Pais Basco orgulha-se de possuir desde séculos um presunto cru que serve de vitrine cultural e de apelo turístico: o presunto de Bayonne”. Ainda segundo o autor, a cidade de Bayonne é conhecida como a capital francesa do presunto cru. Aqui não estamos longe da 
Patrimônio cultural na contemporaneidade: discussões e interlocuções...

forma como as emoções jogam um importante papel à construção cultural do lugar. De acordo com o autor,

[...] trata-se de uma construção cultural do lugar por um produto, mas também por uma emoção vivida em comum sobre o modo da partilha, da troca e da convivialidade e por um saber-degustar singular: o presunto cru é degustado frito e quente, mais frequentemente acompanhado de ovos no prato de Piperade [receita emblemática da cozinha basca feita à base de carne, peixe e ovos]. (ETCHEVERRIA, 2003, p. 40 , tradução nossa).

Conforme argumenta Etcheverria (2003), após a Segunda Grande Guerra, dois fatores contribuíram para a crise do presunto de Bayonne: o processo de intensificação da criação de porcos e, nos anos 1970/1980, as mudanças nos padrões de hábitos alimentares ligados a uma dieta mais saudável, que preconizava a diminuição do consumo de alimentos gordurosos. O presunto de Bayonne sofre isso que Etcheverria (2003) chama de processos de "descaracterização" da produção, com a consequente perda de um importante componente identitário étnico. De acordo com o autor, depois da introdução da produção massificada de presunto em todo e qualquer lugar, os bascos se apropriavam de algo produzido em massa em qualquer lugar e de qualquer forma. Lentamente os bascos não mais queriam se reconhecer e ser reconhecidos através do presunto de Bayonne. Nas palavras do autor: "[...] a denominação presunto de Bayonne conhece um deslocamento semântico desvalorizando o vivido de forma pejorativa: ela torna-se sinônimo de 'presunto do país', isto é, confundida com uma denominação genérica e, portanto, banalizada" (ETCHEVERRIA, 2003, p. 43, tradução nossa).

Em linhas gerais, o presunto cru de Bayonne deixou de ser visto como uma produção cultural própria da identidade basca e forte elemento demarcador frente a outras identidades. Será necessário recuperar toda a cadeia do terroir para que o presunto de Bayonne volte a gozar de forte prestígio entre os bascos. A análise de Etcheverria ganha apoio nas ideias de Régnier et al. (2006, p. 83, tradução nossa), quando afirmam que “[...] mais geralmente, a moda do terroir 
constitui uma forma de resistência a uma uniformização dos gostos que seria ligado às evoluções da indústria agroalimentar.” Nos anos 1980, momento em que se observa um acirramento da resistência aos processos de uniformização dos gostos localmente marcados, produtores locais resolvem retomar a produção do presunto cru de Bayonne, segundo o modo tradicional de fazê-lo. O objetivo central é o de reviver o gosto autêntico e ancestral do presunto, comenta Pierre Otéiza, produtor local (ETCHEVERRIA, 2003, p. 45).

Através da reinvenção do presunto de Bayonne sob a forma de dois novos produtos, o presunto cru de Ibaïona, nome basco, e o presunto de porco basco, procede-se à "redescoberta do gosto do passado e a qualidade tradicional” (ETCHEVERRIA, 2003). Pregase aqui um retorno ao lugar através de um trabalho de memória coletiva e de reapropriação de determinados traços de história e de culturas alimentares. Passam a ser enfatizados o saber-fazer e o saber-degustar através de uma produção localizada e relocalizada de alta qualidade. Com o caso do presunto de Ibaïona e do presunto de porco basco vemos de que forma se arma o processo de reidentificação e reafirmação identitária através do trinômio terroir-cultura-identidade.

Segundo Etcheverria (2003), esses dois elementos - presunto cru de Ibaïona e presunto de porco basco - participam da reativação de tradições gastronômicas que asseguram a identidade basca, em que as práticas culinárias constituem uma arte. A reativação do laço (presunto - lugar - cultura/identidade) nutre o sentimento de pertencimento regional basco e constitui uma forma de emergência identitária que, entretanto, não se situa no nível político. Além disso, foi fundamental a participação de restaurantes gastronômicos bascos e de Paris. Segundo o autor, "Os presuntos crus tornam-se e retornam-se marcadores territoriais, signos simbólicos conotando o espaço basco. Eles possuem notadamente entre os Bascos uma dimensão nostálgica evidente que redefine a dialética continuidade-ruptura cultural” (ETCHEVERRIA, 2003, p. 51, tradução nossa).

Nas ponderações de Roger Chartier (1990), ao abordar conceitos como cultura, o pesquisador parte do princípio de que é necessário pensar sobre essa categoria com especial atenção à base conceitual própria de um tempo e de um espaço para poder compreendê-la 
enquanto um processo. Tal proposição convida a uma reflexão acerca dos movimentos sociais e culturais mais amplos que estão em curso na sociedade contemporânea e que dialogam com a categoria do patrimônio. Categoria hoje indispensável para o resgate e a inscrição de novos e/ou velhos "lugares de memória", bem como para a afirmação de elementos identitários oriundos do campo da cultura, como foi possível observar com os trabalhos de Etcheverria (2003) e de Noyes (2011).

O patrimônio converte-se, assim, em uma categoria de pensamento fundamental para a construção da memória e da identidade, capaz de integrar, em um amplo campo de disputas, a pluralidade das representações culturais que buscam se afirmar diante dos mecanismos de padronização que o fenômeno da globalização impõe. Como pontuado por Nunes (2017, p. 175), para a historiografia, espera-se colaboração e disponibilidade "[...] para a investigação aplicada e para a colaboração em modalidades de formação inicial e contínua, bem como maior rigor na estruturação de discursos ao mesmo tempo adequados a cada público/situação e contextualizadores/problematizantes”.

Ainda de acordo com Nunes (2017, p. 170), os temas que tiveram êxito na década de 1960 que englobam aspectos intrinsecamente ligados a "ideologias e instituições políticas, relações diplomáticas e conflitos militares, estruturas sociais e actividade económica, elites e cultura erudita, entre outros [...]”, durante tempos foram esquecidos e, a partir desse contexto, devem ser aplicados tanto nas concepções teóricas quanto práticas das intervenções no âmbito do patrimônio cultural. Da mesma forma que a cultura material/imaterial vai sendo incorporada enquanto discurso, para além da pedra e cal, e inovando vertentes que possam desconstruir o funcionamento de instituições que colaboram na intenção de revelar os propósitos da historiografia, da memória histórica e da composição do patrimônio da sociedade na sua contextualização prática.

Há especificidades, por exemplo, no processo de experimentação da memória que os indivíduos que estão mergulhados no fenômeno da globalização vivenciam e que precisam ser apreendidas. Especificidades que passam, nesse caso, pela perspectiva de afirmação do que denominou Bourdieu de "capital simbólico" e 
que, sem dúvida, permeiam o engajamento dos atores sociais na inscrição e afirmação de seus "lugares de memória" como "novos patrimônios”. É por isso que a memória constitui-se como uma valiosa ferramenta teórico-metodológica capaz, inclusive, de engendrar, no âmbito do vivido, novos processos de experimentação da perspectiva patrimonial.

Jacques Le Goff (1996) acredita que a memória se ocupa mais da ideia de coletividade do que de rememorações individuais, pois, como meio de conservar informações, reelabora a representação do passado e elenca o que se define como mais ou menos relevante em termos de grupo/coletivo. As questões de formação da memória coletiva passam, para o autor, pelo crivo das lutas pelo poder, especialmente porque grupos, raças, gêneros e etnias "esquecem" ou "lembram" aquilo que lhes permite o domínio, a força e os mecanismos de manipulação e manutenção da esfera coletiva. Conforme assinala Le Goff (1996, p. 57), "[...] a memória coletiva não é apenas uma conquista: é também um instrumento e um objectivo de poder, [...] também a luta pelo domínio da recordação e da tradição, esta manifestação da memória”.

É a memória coletiva um importante instrumento permeado pelo poder que pode, no caso das sociedades orais, ancorar-se no domínio da recordação, para assegurar a manutenção de seus elementos mais tradicionais. $\mathrm{O}$ embate aqui se dá no domínio da manutenção da capacidade do próprio ato de recordar e rememorar. Embate que é vivenciado permanentemente pelos grupos sociais que se encontram mergulhados em um mundo globalizado. Recordar e rememorar são ferramentas fundamentais para a inscrição e inserção social dos ricos elementos das singularidades locais.

Já Thompson (2005) acredita que a memória está associada à capacidade de compreensão do indivíduo e, em especial, ao seu interesse em manter viva a lembrança. $\mathrm{O}$ autor destaca ainda que, independentemente de qual seja o motivo e a precisão dessa memória, esta corresponderia ao interesse e necessidade sociais, podendo ser infimamente maior quando há interesses de grupos sobre ela.

Convém sublinhar que a memória, por sua vez, preserva vínculos estreitos com o "tempo", construção social das mais importantes e expressivas na formação de laços identitários. Para Koselleck (2006), 
por exemplo, o que constitui o tempo histórico são as concepções sociais sobre temporalidade e seu futuro, debate no qual a temática historiográfica não é propriamente o passado, mas o futuro, e esse tempo é oriundo da tênue fronteira entre as experiências e tensões e as expectativas entre o passado e o futuro.

Pode-se afirmar, então, tomando como referencial essa reflexão de Koselleck, que a formação do patrimônio passa também pela eleição de aspectos do passado que permitirão sua vivência no futuro. $\mathrm{O}$ que fica enquanto documento e monumento depende da elegibilidade que o grupo/coletivo definiu enquanto promissor. Nessa perspectiva, os fundadores da escola dos Annales partem do princípio de que a História não pode separar o estudo do passado do presente e do futuro, pois olhar para o passado na busca da compreensão dos fatos do presente é uma das leituras do saber histórico e suas temporalidades. Toda História se faz a partir do tempo presente, e desse "exercício do fazer histórico" emerge uma "escrita da História” que deixa, muitas vezes, "ecos" ao longo de múltiplas temporalidades.

A constituição do patrimônio e sua experimentação ocorrem no bojo desse movimento mais amplo da própria perspectiva de História, fundindo-se e, por vezes, confundindo-se com esses "ecos" que atravessam os tempos históricos, preservando elementos identitários profundos. Elementos que, ao emergirem, refundam e (re) significam velhos "lugares de memória", em torno, muitas vezes, de novas identidades coletivas.

Outras denominações apropriadas pelo patrimônio giram em torno do seu corpus físico, ou seja, as funções e relações entre documento e monumento. $\mathrm{O}$ monumento tem como característica o poder de perpetuação das sociedades históricas, sendo ele derivado da memória coletiva, com sua construção a partir dos testemunhos escritos. Tal reflexão, proposta por Jacques Le Goff (1996), desvela assim outro aspecto importante que também se vincula à construção dos bens patrimoniais: o papel e o alcance dos registros escritos como espaços de inscrição de elementos identitários.

Le Goff (1996) contribui, na perspectiva da historiografia francesa, ao apontar novas leituras acerca do patrimônio enquanto objeto de análise, especialmente oriundas das relações com a memória 
(NORA, 1992), com o tempo (KOSELLECK, 2006) e com as representações culturais (CHARTIER, 1990). Le Goff contribui também ao discutir as estratégias das sociedades para relacionar os bens aos seus valores. O tempo, segundo François Hartog (2013), é apreendido pela humanidade ao estabelecer diferentes regimes de historicidade. Em outras palavras, como presume Pacheco (2017, p. 8), "a prática de eleger determinados objetos materiais e imateriais como patrimônio histórico seria, assim, mais uma estratégia, em meio a outras, de as comunidades se relacionarem com seu tempo".

Nesse sentido, os objetos que se produzem temporalmente vão assinalando novas percepções, como documentu, docere ou "ensinar", alternando sua significância para "prova", aquilo que comprova algo. Em meados do século XVII, a expressão titres et documents credita à linguagem jurídica a histórica, tendo o sentido moderno de testemunho histórico apenas no século XIX. A prova histórica admite apenas no final do século XIX e início do XX o documento como fundamento do fato histórico, por meio da escolha e uso do historiador, mas eleva o saber histórico ao uso do documento como prova e fonte.

No final do século XIX, Fustel de Coulanges foi o testemunho do uso e validade do documento e monumento para os historiadores em suas pesquisas e validações, sobressaindo-se os termos como formas de validar o "fato". E, ao retirar dos documentos tudo o que eles contêm e não lhes acrescentar nada do que eles não contêm, terão como missão e ofício a manutenção o mais próximo possível dos textos (LE GOFF, 1996, p. 96). Já o termo "monumento" foi utilizado apenas no século XIX para as grandes coleções de documentos, destacando-se um conjunto de palavras que serviriam de provas, instrumentos, testemunhos, entre outros que almejavam o "como" organizar novos métodos e instrumentos da memória coletiva e da história, a fim de provar cientificamente como fins de prova histórica.

O "como se faz uma história" dentro das experiências e expectativas, assim como a posição do historiador no momento em que faz a história ou as histórias das ideias, é o princípio da relação presente/passado e futuro, e a comprovação disso passa pelo uso da prova, ou seja, dos documentos que corroboram a formação dos 
Patrimônio cultural na contemporaneidade: discussões e interlocuções...

saberes históricos sobre determinadas temporalidades. $\mathrm{O}$ patrimônio se conjuga exatamente nesse ínterim, em que o monumento/ documento ou mesmo o registro e as vozes são capazes de formar um elo com o tempo/espaço por meio do que ainda existe, mesmo que na memória.

$\mathrm{Na}$ ideia de formação do patrimônio pela perspectiva imaterial, o registro de bens muitas vezes conta com a história contada pelos guardiões da memória. Os arquivos, por exemplo, independentemente do que guardam, são formados a partir de uma proposta da modernidade, iniciada pelo Iluminismo, e vêm da formação do Estado Nacional, a partir de 1789, com o legado da Revolução Francesa, no período em que a sociedade começa a ter necessidade de guardar suas lembranças e memórias. Criam-se então três modalidades institucionais de preservação de memória: os arquivos, museus e as bibliotecas nacionais (CAMARGO, 2006, p. 34).

Assim, o processo de formação do patrimônio cultural, para melhor ser compreendido, deve ser pensado a partir da relação que estabelece com o campo histórico e outros campos do conhecimento, já que apresentam olhares metodologicamente diversificados, porque são objetos também complexos. Olhares e formas de apreensão do processo de patrimonialização que enriquecem não só a percepção da noção de memória, como também colocam questões acerca das formas de apropriação e preservação dos elementos constitutivos da identidade coletiva, bem como da formação e afirmação dos "lugares da memória" (NORA, 1992) e suas possibilidades de uso. É importante ressaltar, por fím, que são significativas as demandas sociais que através da perspectiva patrimonial se presentificam e, dessa forma, convertem os bens patrimoniais e seus campos de sentidos em História.

Para Pacheco (2017, p. 13), fica implícita a necessidade de ampliação do campo historiográfico acerca do patrimônio, pois

O estudo histórico dos objetos do patrimônio cultural material e imaterial é, portanto, uma temática que precisa ser observada pelos historiadores com mais atenção. Praticamente todos os temas de pesquisa histórica baseados em documentação escrita podem encontrar reforço com a

Anos 90, Porto Alegre, v. 25, n. 48, p. 51-86, dez. 2018 
observação e análise de objetos culturais materiais ou imateriais que os cercam. Perceber essa potencialidade implica aprimorar as ferramentas teóricas e metodológicas para essa análise. Tarefa para uma nova geração de historiadores.

Desse modo, podemos dizer que o patrimônio vem sendo questionado e ampliado em termos conceituais e aplicado, seja por metodologias mais participativas ou pelos próprios órgãos de fomento e controle, como nova forma de perceber democraticamente a memória e a história das sociedades pelas características da vida material e simbólica das diversas comunidades, a fim de garantir um conceito mais amplo e de significâncias múltiplas e não direcionais na história hegemônica da sociedade capital.

No Brasil, pensar sobre a história do patrimônio cultural requer estabelecer o reconhecimento da sua produção na multiplicidade de temas, abordagens, enfoques, trajetos e fontes, além dos encaminhamentos que buscam entrecruzar métodos e teorias para se inscrever o patrimônio, especialmente a partir dos anos de 1970, quando algumas abordagens foram privilegiando críticas e debruçaram-se sobre o tema (ABREU; CHAGAS, 2003; CHUVA; NOGUEIRA, 2012).

Nesse contexto, nova relação entre patrimônio cultural e identidades amplia-se em consonância com o dever de memória, desdobrando as relações entre o global e o local, valorizando aspectos tangíveis e intangíveis, estabelecendo-se o campo do patrimônio como direção onde há a necessidade de reflexões ampliadas do conceito de nacional, agora motivadas por outras dimensões de pertencimento e de valoração (CHUVA, 2012).

\section{Considerações finais}

Os incontáveis movimentos de reivindicação identitária ocorridos ou ainda em curso em diferentes regiões do mundo, assim como lutas em torno da valorização de patrimônios de diferentes naturezas, refletem importantes mutações no campo da cultura, da identidade, do patrimônio e da memória.

Anos 90, Porto Alegre, v. 25, n. 48, p. 51-86, dez. 2018 
Patrimônio cultural na contemporaneidade: discussões e interlocuções...

Os trabalhos que se colocam em discussão atestam, em diferentes partes do mundo, tensões, conflitos e disputas pela valorização patrimonial como ferramenta de afirmação ou reivindicação identitária. Em alguns casos, busca-se valorizar determinado patrimônio como forma de lutar pela salvaguarda de modos de vida cultural em vias de desaparição, como nos exemplos do pastoreio de transumância ou do presunto cru de Bayonne. Em outros casos, denuncia-se a patrimonialização como processo responsável por afastar o patrimônio como vivência daqueles que o suportam e o dinamizam em momentos festivos efervescentes, como a festa da Patum de Berga, na Espanha.

Em termos metodológicos, ganham importância as abordagens qualitativas oriundas das epistemes sociológica e antropológica relacionais. Isto é, métodos e técnicas que privilegiam os atores sociais locais, seus ritos, mitos, falas e narrativas organizadas sob a forma de sistemas de pensamento que situam e valorizam objetos, práticas e discursos como sendo fundamentais na construção de suas memórias e tradições. Como assinala Amirou (2000), é o imaginário um fato antropológico que transforma uma localidade neutra em patrimônio. Gonçalves (2002) também enfatiza a importância das metodologias qualitativas, notadamente a etnografia, para se apreender aspectos como a ressonância, isto é, em que medida os agentes sociais mantêm estreitos laços com seus patrimônios.

O patrimônio, ao mesmo tempo categoria de pensamento e experimentação viva, vem estabelecendo um diálogo permanente e profícuo com as noções de memória, cultura, "tempo" e identidade, amplamente trabalhadas no campo histórico. Desse diálogo surgem e se renovam, na contemporaneidade, em seu embate permanente com a perspectiva de homogeneização que o advento da globalização imputa, novos mecanismos e estratégias para a constituição, afirmação e consolidação de bens patrimoniais, que trazem à tona elementos identitários expressivos que marcam e sublinham as ricas especificidades locais.

Do diálogo permanente com esses aportes teórico-metodológicos, derivam ações práticas e concretas que visam sublinhar o amplo mosaico das "representações culturais". O patrimônio é, assim, cotidianamente (re)inventado não apenas pelas instituições 
que se encontram no interior do Estado-nação, mas também por múltiplas coletividades que buscam reconhecimento e inserção social em sociedades complexas. Dessa forma, os mecanismos de experimentação da memória não só resgatam lembranças, como também lhes atribuem valor e sentido. Afinal, a memória, em seu amplo sentido, requer o pensar nas lembranças que tiveram valor em destaque para as pessoas, espaços, lugares e histórias, mas que não se esgotam nelas.

É a própria memória, suportada pelos membros das culturas ditas populares e cuja marca é a pluralidade, que dessa forma incita o pensar sobre o papel e o alcance das manifestações de sentido popular que vêm sendo incorporadas na concepção de "usos", ou mesmo de apropriações por sujeitos que requerem a guarda desses objetos. Ao categorizar a perda como uma retórica, Gonçalves (2002) interpreta alguns discursos sobre o patrimônio cultural brasileiro como "estratégias de objetificação cultural" ao serem apropriadas por entidades de preservação como meios de garantir o futuro da identidade.

Gonçalves (2002) também reflete acerca do patrimônio imaterial como mediador importante dos aspectos da vida social e cultural das concepções mais tradicionais de gerações inteiras para outras. $\mathrm{O}$ autor considera lugares, festas, religiões, formas de medicina popular, música, dança, culinária, técnicas, entre outros aspectos, como centrais ao processo de produção de sentido negociado entre os atores sociais e cujo acompanhamento se mostra imprescindível.

Os discursos sobre o patrimônio cultural se baseiam, então, em narrativas históricas ou antropológicas sobre a memória e a identidade nacionais ou locais, ou seja, em narrativas referentes a sujeitos, tempos e eventos e personagens históricos que corroboram a formação de valores que constroem a identidade em diferentes níveis, mas ainda assim imbuídas de mitos e alegorias que dão forma aos objetos e sentidos valorativos. Os valores de uma dada localidade, estado ou país passam a ser definidos ou imaginados por meio de ilustrações, imagens em forma de objetos, coleções, monumentos, cidades históricas, entre outros, e a partir disso se formam os conceitos e as definições de identidades. 
A História, eleita por meio de seus objetos de análise e evidência, acaba sendo um campo de disputas e definições, pois seleciona os objetos de memória que significam e produzem o patrimônio cultural, tangenciado e legitimado pelo poder simbólico exercido. E o Estado, por meio de seus instrumentos de preservação e conservação e sua institucionalização desse processo, privilegia a sua transformação de objeto mercantilizável ao não conseguir efetivamente sanar as direções do que e como será a conservação dos bens e, reciprocamente, a sua preservação.

A noção de patrimônio, percebida pela interpretação, apreensão e experimentação do passado, dialoga e se associa aos processos de uso, apropriação e preservação vinculados às vivências relativas à memória, à identidade, ao "tempo", à cultura e à própria história. Essa construção do patrimônio, a partir das óticas diversas que figuram na disputa pela definição, conceitualização e preservação de memórias conjugadas com base em sua relevância ou fatuidade para a sociedade, além de tentar ressaltar o papel da memória como um dos elos com esse formar e reformar do passado, que também se confirma como presente e futuro, traz à luz dos saberes diversos o compromisso de reelaborar a ideia de criação e manutenção dos monumentos e documentos do passado enquanto formas de interação social, de valorização temporal e de laços com as memórias criadas e recriadas ao longo da história da humanidade, não mais como um modelo trazido no ideário modernista, mas numa renovação de valores e vínculos com as diversas temporalidades e suas significâncias para a sociedade. Ele se apresenta como um convite à anamnese coletiva, ao "dever" da memória, como menciona Hartog (2006, p. 266), "com suas exigências de conservação, de reabilitação e de comemoração".

Para encerrar as relações necessárias ao futuro das discussões sobre o patrimônio enquanto um campo do saber apropriado e almejado por tantas áreas do conhecimento, podemos destacar a sua relevância enquanto elemento da história e da memória social das diversas sociedades, com apelo ao passado como produto da valoração que se dá ao longo das diversas temporalidades na dinâmica da cultura. Há muito ainda por receber colaboração, a pensar 
nas propostas de análise da Antropologia, História e Sociologia, além da Arquitetura.

Corroborando a nova proposta para o campo do patrimônio cultural, tendo por referência as reflexões de Nogueira (2014), é a partir da memória e da transitoriedade das identidades que se pode ampliar a compreensão do ato de patrimonializar, mas sem esquecer que essa direção "nem sempre constrói e preserva identidades", e o futuro do patrimônio depende de novas intervenções e sentidos da memória social enquanto formato na compreensão da relação material/imaterial não como dicotomia, mas como unidade. $\mathrm{Ou}$ ainda, como percebe Paiva (2015), nos dilemas atuais estão as relações entre o presente, no "horizonte de expectativas", e os vínculos identitários, que os conectam ao passado. Para ele, essa "tensão entre ambas as temporalidades (presente e pretérito) constitui um dos muitos desafios presentes no campo do patrimônio cultural" (p. 233). E, nessa concepção, o patrimônio muito tem a beber na História, na Antropologia e na Sociologia para compor metodologias e teorias sobre os processos e objetos de valor temporalmente constituídos pelas sociedades.

\section{CULTURAL HERITAGE IN CONTEMPORANEITY: DISCUSSIONS AND DIALOGUES ON THE FIELDS OF THIS KNOWLEDGE}

Abstract: Patrimony as a social practice of construction and presentification of collective identities that express individual, collective and public interests, over the years has been rethought and reorganized from disputes that intervene in history, in memory and in its various senses, which are politically, economically and socially. This article intends to contribute to the theoretical and methodological approaches that the various fields of knowledge have added to the reflection, apprehension and relativization of the perceptions of the field "historical and cultural patrimony" as a form of conceptual application and social criticism, in order to expand the most varied methods and theories on the "uses" of the patrimony as tool of patrimonialization, awareness and even amplification of the relations of patrimony with the society. In Brazil, the discussions permeate the areas of Architecture, History, Anthropology, Law and Tourism, being more salient in certain branches due to its appropriation. As a practice, indifferent to the themes, it reflects the local, regional and national aspirations and experiences, while at the same time signaling the conceptual 
Patrimônio cultural na contemporaneidade: discussões e interlocuções...

displacements between memory and temporal valorization, the interdisciplinary challenge that touches all the discussions is urgent of the conceptual revision, to approach the relations between the different fields of knowledge that has been preparing to promote the debate about the use and concept of the heritage. Keywords: Cultural heritage. Theories. Methodologies. Identities. Memories.

\section{$\infty$ Referências}

ABREU, Regina; CHAGAS, Mario. Memória e patrimônio: ensaios contemporâneos. Rio de Janeiro: Ed. DP\&A, 2003.

AMIROU, Rachid. Imaginaire Du tourism culturel. Paris: PUF, 2000.

ANDRADE, Mário de. Crônicas de Malazarte VIII. In: BATISTA, Marta Rossetti; LOPEZ, Telê Porto Ancona; LIMA, Yone Soares (Org.). Brasil: 1ํㅡㄹ tempo modernista, 1917/29: documentação; pesquisa, seleção, planejamento. São Paulo: Instituto de Estudos Brasileiros, 1972. p. 109-115.

. Cartas de trabalho (Aspectos da Literatura Brasileira). Brasília, DF: MEC/SPHAN/FNpM, 1981.

BARBAS, Marie-Gravari; VOILIER, Philippe. Lieux de culture, culture des lieux. Productions(s) culturelle(s) locale(s) et émergence des lieux: dynamique, acteurs, enjeux. Rennes: Presses Universitaires de Rennes, 2003.

BOURDIEU, Pierre. Esquisse d'une théorie de la pratique. Paris: Seuil, 2000.

. A economia das trocas simbólicas. 5. ed. São Paulo: Perspectiva, 2007.

CAMARGO, Haroldo Leitão. Patrimônio Histórico e Cultural. São Paulo: Aleph, 2002.

CASTRIOTTA, Leonardo Barci; ARAÚJO, Guilherme Maciel. Patrimônio, valores e historiografia: a preservação do conjunto habitacional do IAPI. Arquitetura Revista, v. 5, n. 1, p. 38-54, jan./jun. 2009.

CAVALCANTI, L. Encontro Moderno: volta futura o passado. In: CHUVA, M. (Org.). A invenção do Patrimônio: continuidade e ruptura de uma política oficial de preservação no Brasil. Rio de Janeiro: IPHAN, 1995. p. 41-53.

CHARTIER, Roger. A História Cultural: entre práticas e representações. Tradução de Maria Manuela Galhardo. (Coleção Memória e Sociedade). Rio de Janeiro: Bertrand Brasil, 1990.

Anos 90, Porto Alegre, v. 25, n. 48, p. 51-86, dez. 2018 
CHOAY, Françoise. O reino urbano e a morte da cidade. Projeto História, São Paulo, v. 18, p. 4-23, maio 1999.

. Alegoria do patrimônio. São Paulo: Estação Liberdade, 2001.

CHUVA, Márcia. Fundando a nação: a representação de um Brasil barroco, moderno e civilizado. TOPOI: Revista de História, Rio de Janeiro, v. 4, n. 7, p. 313-333, jul./dez. 2003.

CHUVA, Márcia; NOGUEIRA, Antonio Gilberto Ramos (Org.). Patrimônio cultural: políticas e perspectivas de preservação no Brasil. Rio de Janeiro: Mauad X, 2012.

CLASTRES, Pierre. A sociedade contra o Estado. Rio de Janeiro: Francisco Alves, 1992.

CUCHE, Denys. La notion de culture dans les sciences sociales. Paris: Le Découverte, 1996.

DURAND, Gilbert. Introduction à la mythodologie: mythes et societès. Paris: Albin Michel, 1996.

ETCHEVERRIA, Olivier. Le Pays Basque réinvente le jambon cru: les jambons Ibaïona et de port basque au service de l'identification culturelle. In: GRAVARI-BARBAS, Maria. Lieux de culture, culture des lieux. Production(s) culturelle(s) locale(s) et émergence des lieux: dynamiques, acteurs, enjeux. Rennes: Presses Universitaire de Rennes, 2003. p. 39-52.

FONSECA, Maria Cecília Londres. O Patrimônio em Processo. Trajetória da política federal de preservação no Brasil. Rio de Janeiro: Editora da UFRJ; MinC/IPHAN, 2005.

GEERTZ, Clifford. A interpretação das culturas. Rio de Janeiro: Zahar, 1978. GIDDENS, Anthony. As conseqüências da modernidade. São Paulo: UNESP, 1991. GONÇALVES, José Reginaldo Santos. A retórica da perda: os discursos do patrimônio cultural no Brasil. Rio de Janeiro: Editora UFRJ; Iphan, 2002.

. Monumentalidade e discurso: os patrimônios culturais como gênero e discurso. In: OLIVEIRA, L. (Org.). Cidade: história e desafios. Rio de Janeiro: Ed. FGV, p. 108-123, 2002.

. Os limites do patrimônio. In: LIMA, Manuel Ferreira et al. (Org.). Antropologia e patrimônio cultural: diálogos e desafios contemporâneos. Blumenau: Nova Letra, p. 239-248, 2007. 
Patrimônio cultural na contemporaneidade: discussões e interlocuções...

. O patrimônio como categoria de pensamento. In: ABREU, Regina; CHAGAS, Mario (Org.). Memória e patrimônio: ensaios contemporâneos. 2. ed. Rio de Janeiro: Lamparina, 2009.

HARTOG, François. Tempo e Patrimônio. Varia História, Belo Horizonte, v. 22, n. 36, p. 261-273, 2006.

HOBSBAWM, Eric. Nação e nacionalismo desde 1780. Rio de Janeiro: Paz e Terra, 1990.

JULIÃO, Letícia. O Sphan e a cultura museológica no Brasil. Estudos Históricos, Rio de Janeiro, v. 22, n. 43, p. 141-161, jan./jun. 2009.

KOSELLECK, Reinhart. Futuro passado: contribuição à semântica dos tempos históricos. Rio de Janeiro: Contraponto, 2006.

LE GOFF, Jacques. História e memória. Campinas, SP: Unicamp, 1996.

MARINS, Paulo Cesar Garcez. Novos patrimônios, um novo Brasil? Um balanço das políticas patrimoniais federais após a década de 1980. Estudos Históricos, Rio de Janeiro, v. 29, n. 57, p. 9-28, jan./abr. 2016.

MAUSS, Marcel. Ensaio sobre a dádiva. Forma e Razão da troca nas sociedades arcaicas. Sociologia e Antropologia, São Paulo, v. II, p. 37-178, 1974.

MENESES, Ulpiano Toledo Bezerra de. O campo do patrimônio cultural: uma revisão de premissas. In: SUTTI, Weber (Coord.). I Fórum Nacional do Patrimônio Cultural: sistema nacional de patrimônio cultural. Desafios, estratégias e experiências para uma nova gestão. Brasília, DF: Iphan, 2012. p. 25-39. MICELI, Sérgio (Org.). Estado e cultura no Brasil. São Paulo: Difel, 1984. . Intelectuais à brasileira. São Paulo: Companhia das Letras, 2001.

NOGUEIRA, Antonio Gilberto Ramos et al. Benfica em três tempos: patrimônio, inventário e memória local. In: CHUVA, Márcia; NOGUEIRA, Antonio Gilberto Ramos (Org.). Patrimônio cultural: políticas e perspectivas de preservação no Brasil. Rio de Janeiro: Mauad X, 2012.

- O campo do patrimônio cultural e a história: itinerários conceituais e práticas de preservação. Antíteses, v. 7, n. 14, p. 45-67, jul./dez. 2014.

NORA, Pierre. Entre memória e história: a problemática dos lugares. Projeto História: História e Cultura, São Paulo, n. 10, 1993.

NOYES, Dorothy. La fête ou le fetiche, le geste ou la géstion. Du patrimoine immatériel comme effet pervers de la démocratisation. In: BORTOLOTTO, Chiara (Org.). Le patrimoine culturel immatériel: enjeux d'une nouvelle catégorie. Paris: Éditions de la Maison des sciences de l'homme, 2011. p. 125-149.

Anos 90, Porto Alegre, v. 25, n. 48, p. 51-86, dez. 2018 
NUNES, João Paulo Avelãs. História e historiografia, património cultural e museologia, lazer e turismo culturais: uma abordagem deontológico-epistemológica e teórico-metodológica. Revista de Teoria da História, v. 17, n. 1, p. 162-182, jul. 2017.

OLIVEN, Ruben. Patrimônio intangível: considerações iniciais. In: ABREU, Reginaldo; CHAGAS, Mário (Org.). Memória e patrimônio: ensaios contemporâneos. Rio de Janeiro: Lamparina, 2009.

ORTIZ, Renato. Cultura brasileira e identidade nacional. São Paulo: Brasiliense, 1994.

PACHECO, Ricardo de Aguiar. O Patrimônio histórico: objeto de pesquisa do historiador. História Unicap, v. 4, n. 7, p. 5-14, jan./jun. 2017.

PAIVA, Odair da Cruz. Imigração, patrimônio cultural e turismo no Brasil. Anais do Museu Paulista, São Paulo, v. 23, n. 2, p. 211-237, jul./dez. 2015.

PAOLI, Paula Silveira de. Patrimônio e historiografia: narrativas modernas do passado da arquitetura. Fórum patrimônio, Belo Horizonte, v. 3, n. 2, p. 1-26, jul./dez. 2009.

PELEGRINI, Sandra. A gestão do patrimônio imaterial brasileiro na contemporaneidade. História (São Paulo), Franca, v. 27, n. 2, p. 145-173, 2008.

REGNIER, Faustine. Un fait social. In: ___. L'exotisme culinaire, essai sur les saveurs de l'Autre. Paris: Presses universitaires de France, 2004.

REGNIER, Faustine; LHUISSIER, Anne; GOJARD, Séverine. Sociologie de l'Alimentation. Collection Repéres. Paris: La Décourvete, 2006.

RICOEUR, Paul. A memória, a história, o esquecimento. Campinas, SP: Editora da UNICAMP, 2007.

SANTOS, Rafael. As cores locais: regionalidade, cultura e turismo. In: PELLEGRINI, Sandra et al. Turismo e patrimônio em tempos de globalização. Campo Mourão: Editora da FECILCAM, 2009. p. 45-69.

SCHWARCZ, Lilia Moritz. O nascimento dos museus brasileiros. In: MICELI, Sérgio. História das Ciências Sociais no Brasil. São Paulo: Vértice/IDESP, 1989.

SCIFONI, S. A construção do patrimônio natural. Tese (Doutorado em Geografia Humana)-Faculdade de Filosofia, Letras e Ciências Humanas, Universidade de São Paulo, São Paulo, 2006.

SILVEIRA, Luciana; BUENDIA, Mercedes. Da invenção da tradição (ou como as tradições nos inventam). Notas sobre a patrimonialização do pastoreio na 
Patrimônio cultural na contemporaneidade: discussões e interlocuções...

Espanha. Horizontes Antropológicos, Porto Alegre, ano 17, n. 36, p. 145-170, jul./dez. 2011.

SIQUEIRA, E. D.; SIQUEIRA, D. C. O. La feijoada: construction de l'authenticité et du terroir gastronomique à Rio de Janeiro. In: ANDRIEUX, Jean-Yves; HARISMENDY, Patrick (Dir.). L'assiette du Touriste. 1. ed. Rennes, França: Presses Universitaires Franco Rabelais ; Presses Universitaires de Rennes, 2013. p. 234-244.

. Vale tudo? Identidade, cultura e patrimônio na pós-modernidade. In: BARBOSA, Elis Regina; SIQUEIRA, Euler David de (Org.). Concepções, memórias e patrimônio cultural: história, sociedade e educação em foco. Curitiba: Prismas, p. 29-55, 2016.

THOMPSON, E. P. Costumes em comum. Estudos sobre a cultura popular tradicional. São Paulo: Companhia das Letras, 2005.

Recebido em: 26/04/2018

Aprovado em: 30/08/2018 